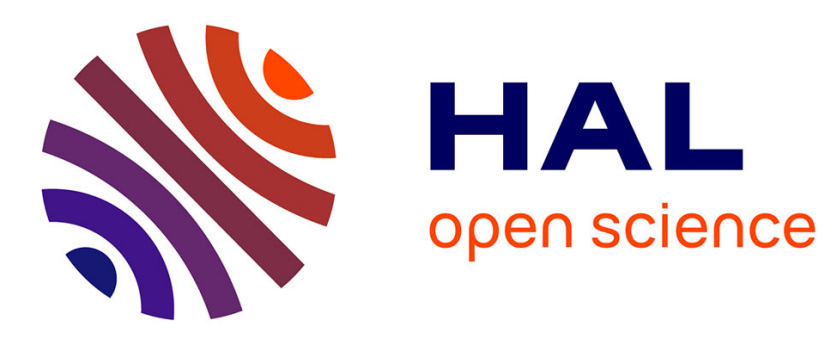

\title{
A 3U cubesat to investigate erbium doped fiber degradation at low earth orbit
}

Arnaud Fernandez, Olivier Llopis, Nicolas Nolhier, Christophe Viallon, Angélique Rissons, Fabien Destic, Stéphanie Lizy-Destrez

\section{To cite this version:}

Arnaud Fernandez, Olivier Llopis, Nicolas Nolhier, Christophe Viallon, Angélique Rissons, et al.. A 3U cubesat to investigate erbium doped fiber degradation at low earth orbit. Avionics and Vehicle FiberOptics and Photonics Conference (AVFOP), Oct 2016, Long Beach, United States. hal-01396269

\section{HAL Id: hal-01396269 \\ https://hal.science/hal-01396269}

Submitted on 14 Nov 2016

HAL is a multi-disciplinary open access archive for the deposit and dissemination of scientific research documents, whether they are published or not. The documents may come from teaching and research institutions in France or abroad, or from public or private research centers.
L'archive ouverte pluridisciplinaire HAL, est destinée au dépôt et à la diffusion de documents scientifiques de niveau recherche, publiés ou non, émanant des établissements d'enseignement et de recherche français ou étrangers, des laboratoires publics ou privés. 


\title{
A 3U cubesat to investigate erbium doped fiber degradation at low earth orbit
}

\author{
A. Fernandez ${ }^{1}$, O. Llopis ${ }^{1}$, N. Nolhier ${ }^{1}$, C.Viallon ${ }^{1}$, A. Rissons ${ }^{2}$, F. Destic ${ }^{2}$, S. Lizy-Destrez ${ }^{2}$ \\ ${ }^{1}$ CNRS, LAAS, Université de Toulouse, UPS, 7 av. du colonel Roche, F-31400 Toulouse, France \\ ${ }^{2}$ ISAE, Université de Toulouse, 10 av. Edouard Belin, BP 54032, 31055 Toulouse, France
}

\begin{abstract}
The next generation of telecommunication satellites operating in the $\mathrm{Ku}$ and $\mathrm{Ka}$ bands consider radio over optical fiber (RoF) technologies as a good candidate for the future flexible payloads. In this context we have started a $3 \mathrm{U}$ nanosatellite dedicated to the qualification of an erbium doped fiber by using an optoelectronic metrology technique. This educational project called NIMPH (Nanosatellite to Investigate Microwave Photonics Hardware) aims to quantify the gain and noise figure degradation due to cosmic ray exposure of this type of fiber during a two years mission at a low earth orbit (LEO).
\end{abstract}

Index Terms - Radio over fiber, cubesat, erbium doped fiber amplifier (EDFA), opto-RF metrology, space environment. Embedded payload

\section{INTRODUCTION}

Since the deployment of the fiber optic telecommunication network in 90's, especially transatlantic link, the erbium doped fiber amplifier (EDFA) became a key device for optical repeater-regenerator [1]. This device has been qualified for submarine optical network while respecting mechanical, hermetical and thermal constraints. Since 2000, the optical link for optical interconnect, fiber sensing in space systems, inter-satellite link or satellite-ground station link, became of great interest for space payload. Nevertheless, the space environment and especially radiation effects have a wide impact on silica materials [2]. Some research works in materials allowed the development of radiation hardened (RadHard) erbium doped fibers for high deposited dose (>100 krad). However these studies didn't present a threshold deposited dose where photobleaching of the $980 \mathrm{~nm}$ pumping could annihilate the dose effect. Moreover, those previous experiments have been carried out in laboratories, with high dose rate at room temperature. Thus, we propose a nanosatellite mission able to compare the degradation at low earth orbit of a RadHard doped fiber (IXfiber) with a Telecom erbium doped fiber in real space conditions. The NIMPH mission consists in a microwave photonics payload embedded into a 3Ucubesat able to reach a $20 \mathrm{krad}$ deposited dose in two years. The NIMPH cubesat is planned to be launched in 2019. After a presentation of the cubesat, the optoelectronic payload and the metrology technique will be developed in this paper.

\section{NIMPH MISSION}

A cubesat mission is an excellent way to develop in-flight experiment. As a $3 \mathrm{U}$ cubesat is an assembly of 3 cubes of $10 \mathrm{~cm}^{3}$, its small size and weight offers the possibility of being piggybacked in a launcher. The counterpart is the restricted orbit choice and standard constraints. For the NIMPH mission, the challenge is to size a photonics payload in two cubesat units able to receive a $20 \mathrm{krad}$ deposited dose on the erbium doped fibers in two years. To reach this target, a first mission study defined an orbit respecting the cubesat standard and the french spatial operation rules (regarding debris and re-entry). A circular orbit has been defined with a radius of $650 \mathrm{~km}$ and an inclination of $98^{\circ}$ thus allowing us to plan the space environment. The orbit choice determines especially radiation, temperature, but also the energy and link budget. Hence the cubesat will be designed according to these mission specifications. At present the feasibility of the mission has been demonstrated and the satellite is in designing phase. Noting that the dose and temperature cycling could have an impact on electronic systems (On board computer, telecommand and telemeasure board, payload pre-processing). A study with the Fastrad Tool is in achievement. An investigation on the trade-off between thermal and radiation effects is in progress so that it could match with the payload specifications.

\section{OptOElECtRonic PAYLOAD ARChitectURE}

A description of the optoelectronic payload prototype is given in this section. The schematic in Fig. 1 represents a conventional erbium doped fiber amplifier (EDFA) delimited by two opto-mechanical switches for the transmission line reference measurement when EDFA is bypassed. The EDFA is also detailed in Fig. 1. It consists of a $10 \mathrm{~m} \mathrm{Er}^{3+}$ doped fiber (Draka eHPW-9) with co-directional pumping @ 974 nm.

From left to right, this payload contains a signal laser (@ $\lambda_{\text {las }}=1549 \mathrm{~nm}$ ) which is directly modulated by a $10 \mathrm{MHz}$ signal chosen for gain measurement purposes, and also because it corresponds to the configuration of one of the foreseen application of this technology: the distribution of a 
frequency reference (clock) signal. Full EDFA gain measurement from small signal to heavy saturation is provided thanks to the variable optical attenuator. The outgoing amplified signal is split by a $3 \mathrm{~dB}$ optical coupler and is respectively photodetected for gain measurement and filtered at $1556 \mathrm{~nm}$ for amplified spontaneous emission (ASE) measurement.

The control modules (laser bias and temperature control) and measuring equipments (power meter, electrical spectrum analyzer) will be reduced thanks to miniaturized electronic circuits.

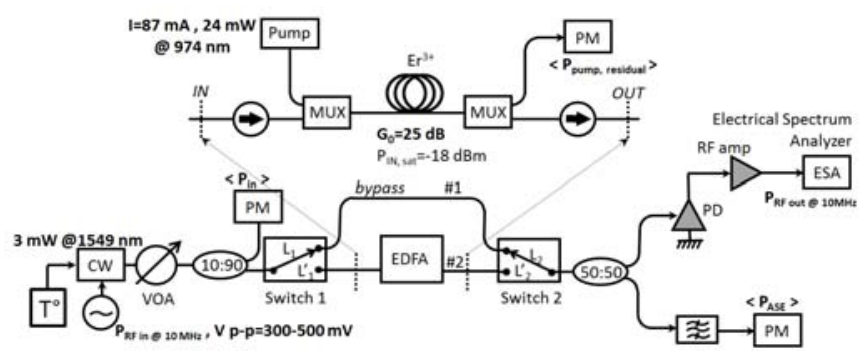

Fig. 1. Schematic of the optical payload architecture devoted to gain and noise figure embedded measurement of EDFA.

\section{MEtRology TEChNIQUE}

The EDFA small signal gain depends on pump laser bias current (Fig. 2). Once the photodetection components are correctly biased, we proceed to the current and temperature control of pump and signal lasers. This last one is directly modulated with a low amplitude voltage @ $10 \mathrm{MHz}$.

By alternatively measuring the electrical power $P_{R F \text {, out }}$ at $10 \mathrm{MHz}$ (with a narrowband power detector) without (\#1, calibration) and with (\#2) the EDFA, one can extract the EDFA optical gain $G_{\text {opt }}$ without being disturbed by ASE noise recovery time (few $\mathrm{ms}$ ), the laser $1 / \mathrm{f}$ noise ( $\mathrm{kHz}$ domain) and its Relative Intensity Noise (GHz domain). Hence by applying the following formula,

$$
G_{\text {opt }}=\sqrt{\frac{\left.P_{R F, \text { out }}\right|_{\# 2}}{\left.P_{R F, \text { out }}\right|_{\# 1}}\left(\frac{L_{1} L_{1}^{\prime}}{L_{2} L_{2}^{\prime}}\right)^{2}}
$$

where $L_{i}$ and $L_{i}$ ' stand for the switch insertion losses, one can precisely quantify the EDFA gain.

This well-known optoelectronic method [3] shows good agreement with an all-optical reference measurement using a power-meter and an optical spectrum analyzer (Fig. 1) usually called optical source substraction method [3].

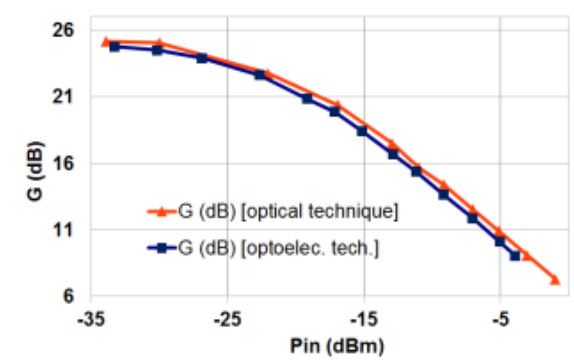

Fig. 2. EDFA gain regarding the signal laser average input power (Ipump $=87 \mathrm{~mA}$ ).

By reasonably neglecting some noise sources like multipath interferences or ASE beating with itself, one can express the noise factor $(F)$ as,

$$
F=F_{\text {sig-sp }}+F_{\text {shot }}=\frac{2 \rho_{A S E}}{h v G_{\text {opt }}}+\frac{1}{G_{\text {opt }}}
$$

by taking into account the ASE to signal laser (in the same polarization state) beat noise $F_{\text {sig-sp }}$ and shot noise $F_{\text {shot }}$ coming from the photodetected averaged signal output power [4]. As expressed by (2), the noise figure calculation requires the measurement of ASE noise $\left(\rho_{A S E}\right)$ at the signal laser wavelength $\lambda_{\text {las }}$ in presence of the laser signal.

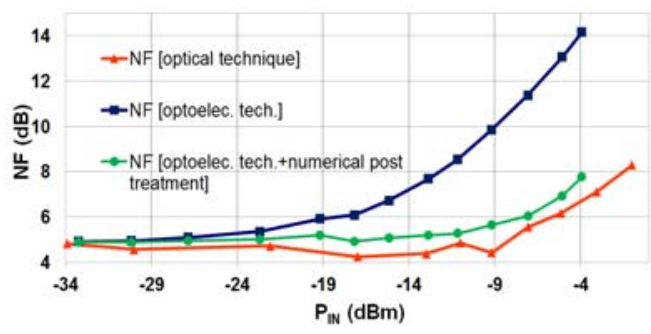

Fig. 3. Comparison between embedded technique (optoelec.), with or without additive numerical post-treatment and reference measurement (optical).

We have chosen a filtering method based on the bandpass filtering of the output noisy spectrum $6 \mathrm{~nm}$ away from the laser carrier $(1556 \mathrm{~nm})$, so that most of the filtered optical signal is ASE noise. Hence by using an interpolation method coupled with a numerical correction that cancel additive amplified laser signal contribution to the filtered ASE, it is possible to accurately recover $\rho_{A S E}$. Experimental results of this technique are given in Fig. 3.

\section{CONCLUSION}

This paper presents the NIMPH project, an educational project started in 2013 aimed to demonstrate the potentialities of EDFA for future Space-enabled Opto-microwave fibered technologies. A method quantifying the gain and noise figure of this type of fiber has been developed and successfully validated using a laboratory test-bench. Radiation and thermal 
tests and studies are in progress. To our knowledge, this is the first time that an Opto-microwave fibered technology is considered to be launched into space.

\section{ACKNOWLEDGEMENT}

We warmly thank CNES, Thales Alenia Space, IXfiber, Sercalo, AdvEOTec and Gooch and Housego for scientific involvement in this project.

\section{REFERENCES}

[1] Y. Maeda, F.Montalti, Optical, Fibres, Cables and Systems, ITUT Manual, 2009

[2] S. Girard et al., "Proton- and Gamma-induced effects on erbiumdoped optical fibers," IEEE Trans. on nuclear science, vol. 54, no. 6, pp. 2426-2434, December 2007.

[3] D. Derickson, Fiber optic test and measurement, New Jersey: Prentice Hall, 1998.

[4] D. Baney, P. Gallion and R. Tucker, "Theory and measurement techniques for the noise figure of optical amplifiers," Optical Fiber Technology, vol. 6, pp. 122-154, 2000. 